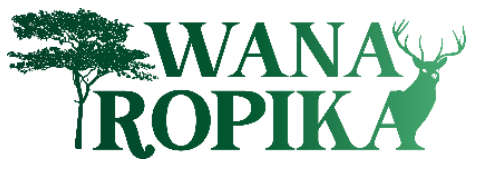

Journal Wanatropika. Vol. 11, No. 2 November 2021

Journal home page: https://jurnal.instiperjogja.ac.id/index.php/JWT/

ISSN: 2088-7019

\title{
PERTUMBUHAN TANAMAN JABON PADA SATU ROTASI (6 TAHUN) DENGAN AWAL TUMPANGSARI PADA HUTAN RAKYAT DI DESA WIDODOMARTANI, KECAMATAN NGEMPLAK, KABUPATEN SLEMAN, YOGYAKARTA
}

The Growth of Antocephalus cadamba at One Rotation (Six Years) with Initial Multicropping on Private Forestland in Widodomartani Village, Ngemplak Sub District, Sleman District, Yogyakarta Province

\author{
Agus Prijono $^{1}$, Sugeng Wahyudiono ${ }^{1}$ \\ ${ }^{1}$ Fakultas Kehutanan Institut Pertanian Stiper Yogyakarta, \\ Korespondensi Penulis: wanatropikajurnal@gmail.com
}

\begin{abstract}
One of main supplier on wood industry is Antocephalus cadamba from private forestland. A. cadamba can be harvested at 6 years with the price of Rp 900,000.00 per cubic meter. A. cadamba has been planted in various areas, one of them in Widodomartani, Ngemplak, Sleman, Yogyakarta Province. The succes silviculture A. cadamba if from planting to harvesting with good practice. One of supported succes planting is used multicropping. This research aims to determine the growth at one rotation (six years) with initial planting used multicropping.Planting is done with a distance of $2 \times 2 \mathrm{~m}$ in the planting. The growth data (height and diameter) was taken in each treatment (6 treatments) and each treatment tree repeated. The data obtained were analyzed by anova and if there were significant differences in the factors, followed by the LSD test. The analysis showed that the treatment is significantly effect agants height and diameter growth. The growth rate of A. cadamba at 6 years planted is $14,48 \mathrm{~m}$ height and 14,61 cm diameter.
\end{abstract}

Key words: Growth, Jabon (Antocephalus cadamba), Initial multicropping

\section{PENDAHULUAN}

Salah satu pemasok utama bahan baku industri kayu ringan berupa tanaman jabon adalah dari hutan rakyat. Jabon (Antocephalus cadamba) dapat dipanen pada umur 6 tahun karena termasuk species cepat tumbuh atau fast growing species. Industri kayu ringan menghasilkan berbagai produk dengan bahan baku jabon, kayu lapis, papan partikel, moulding, furniture, rumah, barecore, papan blok (laminated board, block board), papan serat (fiber block) 
dan sebagainya (Mansur dan Tuheteru, 2011, Kabe dkk, 2013, Suprihanto, 2013, Mintarjo, 2018). Harga jabon berupa log per $\mathrm{m}^{3}$ sekitar Rp 900.000,-. Keberlanjutan Industri Kayu Ringan sangat tergantung pasokan salah satu bahan baku berupa kayu jabon yang pada umumnya ditanaman di areal hutan rakyat. Keberhasilaan hutan rakyat jabon bisa diwujudkan dengan baik jika dalam budidaya dilakukan secara baik dari mulai bibit yang baik, penanaman, perawatan dan pemanenan. Salah satu yang mendukung keberhasilan budidaya utamanya dalam penanaman adalah menggunakan sistem tumpangsari.

Sistem tumpangsari pada awal penanaman sangat baik karena dengan sitem ini yang ditanam awal dengan tanaman pertanian menyebabkan perawatan awal sampai tanaman jabon dapat berhasil sekitar umur 1,5 tahun dapat dilaksanakan dengan baik, karena keberhasilan tanaman awal sangat terkontrol karena petani hutan rakyat sangat intensif dalam menangani tanaman tumpangsari yang otomatis pertumbuhan tanaman pokok jabon tumbuh dengan baik. Setelah tanaman berumur sekitar 1,5 tahun, pemeliharaan sudah dilakukan lebih ringan, terutama kegiatan pemantauan gangguan gulma, hama dan penyakit. Gangguan yang sangat berpengaruh adalah adanya gulma merambat dan hama penggerek batang. Apabila pemeliharaan dilakukan dengan baik maka pada waktu tanaman jabon berumur 6 tahun sudah bisa dipanen karena pertumbuhannya sangat cepat.

Pertumbuhan Jabon sangat cepat baik meninggi dan membesarnya sehingga pada umur 6 tahun sudah dapat dipanen dibanding kayu lainnya, termasuk tanaman sengon (Anonim, 2010a). Jabon putih agar tumbuh optimal perlu dijaga kelembaban tanahnya (Sumarno, 2012). Jabon mempunyai sifat self pruning yang cukup kuat sehingga pada masa pertumbuhan cabagang akan rontok dengan sendirinya dengan demikian tanaman tidak memerlukan pemangkasan (Setyaji, 2011). Sumarno (2012) mengemukakan bahwa agar tanaman Jabon terhindar dari gangguan hama dan penyakit serta multihasil sebaiknya ditanam dengan pola tanam tumpangsari (agroforestry). Umur tanaman jabon 4 sampai dengan 6 tahun sudah dapat dipanen (Mulyana, dkk, 2012). Pustaka lain menyebutkan bahwa tanaman jabon sampai umur 8 tahun pertambahan tinggi per tahun $3 \mathrm{~m}$ dan pertumbuhan diameter $3 \mathrm{~cm}$ per tahun (Anonim, 2010b). Wahyudi (2012) mengemukakan bahwa tanaman jabon di kecamatan Mandau,Talawang, Kabupaten Kapuas, Provinsi Kalimantan Tengah, rata-rata pertumbuhan tingginya per tahun sampai umur 12 tahun $1,21 \mathrm{~m}$ dan pertumbuhan diameternya $1,82 \mathrm{~cm}$ dengan jarak tanam 3x3 m. Prijono (2013 a) melaporkan bahwa umur 18 bulan rata-rata tingginya 4,87 $\mathrm{m}$ dan diameter 5,31 cm. Sulaksono dkk., (2013) melaporkan juga bahwa sampai April 2013 dengan jarak tanam 2 x 2 m di kecamatan Ngemplak, Kabupaten Sleman, Provinsi DIY rata-rata pertumbuhan tinggi per tahun sampai umur 2 tahun adalah 4,19 m dan 
diameter 7,17 cm; di Kecamatan Godean Kabupaten Sleman jarak tanam 2x1,5 m per tahun tinggi 4,12 m dan diameter 7,18 cm; di Kecamatan Bawen Kabupaten Semarang Jawa Tengah jarak 3x3 m per tahun tinggi 3,76 $\mathrm{m}$ dan diameter $9,05 \mathrm{~cm}$. Tanaman jabon pada umur 30 bulan dengan jarak tanam 2x2 m di Widodomartani, Ngemplak, Sleman tingignya 8,46 m dan diameter 7,54 cm (Prijono, 2013 b). Pada umur 4 tahun tingginya 13,59m dan diameter 10,71 cm (Prijono, 2016). Krisnawati dalam Sumarno (2012) mengemukakan tentang riap volume rata-rata dan potensi volume jabon dalam berbagai kualitas tempat tumbuh dan umur serta pendugaan volume jabon berdasar diameter yaitu tempat tumbuh kurang baik jika pada umur 5 tahun riap volume rata-rata sebesar $10 \mathrm{~m}^{3} / \mathrm{ha} / \mathrm{th}$ atau volume saat panen $50 \mathrm{~m}^{3} / \mathrm{ha}$, tempat tumbuh sedang jika pada umur 5 tahun riap volume rata-rata sebesar $15 \mathrm{~m}^{3} / \mathrm{ha} /$ th atau volume saat panen $75 \mathrm{~m}^{3} / \mathrm{ha}$, dan tempat tumbuh yang baik jika pada umur 5 tahun riap volume ratarata sebesar $20 \mathrm{~m}^{3} / \mathrm{ha} /$ th atau volume saat panen $100 \mathrm{~m}^{3} /$ ha sedangkan pendugaan volume jika diameter setinggi dada/DBH $5 \mathrm{~cm}$ perkiraan volume batang $0,01 \mathrm{~m}^{3}$, diameter setinggi dada/DBH $10 \mathrm{~cm}$ perkiraan volume batang $0,03 \mathrm{~m}^{3}$, diameter setinggi dada/DBH $15 \mathrm{~cm}$ perkiraan volume batang $0,06 \mathrm{~m}^{3}$, diameter setinggi dada/DBH $20 \mathrm{~cm}$ perkiraan volume batang $0,16 \mathrm{~m}^{3}$, diameter setinggi dada/DBH $25 \mathrm{~cm}$ perkiraan volume batang $0,31 \mathrm{~m}^{3}$.

\section{BAHAN DAN METODE}

Penelitian dilaksanakan di hutan rakyat jabon di Desa Widodomartani, Kecamatan Ngemplak, Kabupaten Sleman, Propinsi Daerah Istimewa Yogyakarta dengan tahun tanam 2011. Penanaman Jabon dengan sistem tumpangsari selama 1,5 tahun, dengan tanaman ketela, kacang tanah dan cabai. Lokasi wilayah Widodomartani dengan koordinat geografis $7^{\circ} 43^{\prime}$ 2,96' LS dan $110^{\circ} 26^{\prime} 26,41^{\prime \prime}$, mempunyai jenis tanah Regosol dan type iklim C (sedang) menurut Smith Ferguson, dengn curah hujan 1.500-2.000 mm/tahun. Alat yang digunakan dalam penelitian adalah pita meter untuk mengukur keliling batang, galah ukur $4 \mathrm{~m}$ dan christenmeter untuk mengukur tinggi pohon, alat tulis dan alat hitung.

Parameter yang diamati dalam penelitian meliputi: diameter tanaman, tinggi tanaman, dan mengamati kondisi fisik tanaman (persentase hidup) dan serangan hama meliputi intensitas serangan serta persentase kerusakan hama.

Data dianalisis dengan analisis varians dengan uji lanjut BNT (Hanafiah, 2014). Pengambilan sampel langsung di lapangan dengan intensitas sampling $100 \%$ untuk kesehatan tanaman berupa persentase tumbuh dan serangan hama (intensitas serangan dan persen kerusakan). Ada 6 kondisi lingkungan untuk pertumbuhan (diameter dan tinggi pohon) yaitu : P1 (relatif lembab/banyak pohon besar, solum tebal= $27 \mathrm{~cm}$ ), P2 (relatif lembab/banyak pohon 
besar,solum agak tebal $=21 \mathrm{~cm}$ ), P3 (relatif agak kering/banyak pohon pisang, solum agak tebal $=22 \mathrm{~cm}), \mathrm{P} 4($ Kering, solum tipis $=16 \mathrm{~cm}), \mathrm{P} 5$ (relatif lembab/banyak pohon besar solum sedang=23 cm ), P6 (relatif lembab/banyak pohon besar, solum agak tipis= $20 \mathrm{~cm}$ ) yang masing-masing perlakuan 3 ulangan. Data dari hasil pengamatan dianalisis varians dan jika ada pengaruh nyata dilanjutkan dengan uji lanjut BNT /Beda Nyata Terkecil.

\section{HASIL DAN PEMBAHASAN}

\section{A. Kesehatan Tanaman}

Kesehatan tanaman berupa persentase hidup dan serangan hama (intensitas serangan dan persen kerusakan) serta penyebab kematian. Persentase hidup tanaman jabon diambil dari pohon yang hidup dalam tiap kondisi lingkungan pada 6 kondisi, yaitu P1, P2, P3, P4, P5, P6. Tanaman jabon pada tiap kondisi juga dicatat serangan hamanya berupa intensitas serangan dan persen kerusakannya, serta penyebab kematian yang hasil perhitungan persentase hidup tanaman dan penyebab kematian serta hamanya dapat dilihat pada Tabel 1 .

Tabel 1. Persentase hidup (\%), penyebab kematian dan serangan hama pada tanaman Jabon umur 6 tahun

\begin{tabular}{lcll}
\hline Perlakuan & Persentase hidup & \multicolumn{1}{c}{ Penyebab Kematian } & \multicolumn{1}{c}{ Serangan hama } \\
\hline P1 & 64,71 & Roboh angina & Ulat daun, penggerek batang \\
P2 & 70,14 & $\begin{array}{l}\text { Roboh angina, } \\
\text { penggerek batang }\end{array}$ & Ulat daun, penggerek batang \\
P3 & 71,74 & Roboh angina & Ulat daun \\
P4 & 48,83 & Kekeringan & Ulat daun \\
P5 & 65,11 & Roboh angina, & Ulat daun, penggerek batang \\
& & Penggerek batang & Ulat daun \\
P6 & 49,12 & Roboh angina & \\
\hline Jumlah & 369,65 & & \\
\hline Rata-Rata & 61,61 & & \\
\hline
\end{tabular}

Tabel 2. Intensitas serangan (\%) dan persentase kerusakan (\%) serangan hama pada tanaman Jabon umur 6 tahun

\begin{tabular}{lcccc}
\hline Perlakuan & $\begin{array}{c}\text { Intensitas } \\
\text { serangan }\end{array}$ & $\begin{array}{c}\text { Persentase } \\
\text { kerusakan }\end{array}$ & Intensitas serangan & Persentase kerusakan \\
\hline P1 & 100 & 7,61 & 2,27 & 50 \\
P2 & 100 & 3,91 & 17,84 & 100 \\
P3 & 100 & 11,36 & 0 & 0 \\
P4 & 100 & 16,19 & 0 & 0 \\
P5 & 100 & 6,64 & 11,47 & 00 \\
P6 & 100 & 7,67 & 0 & 0 \\
\hline Jumlah & 600 & 53,38 & 31,54 & 250 \\
\hline Rata-rata & 100 & 8,89 & 5,26 & 41,67 \\
\hline
\end{tabular}

Tabel 1 menunjukkan bahwa persentase hidup tanaman jabon (Antocephalus cadamba) pada umur 6 tahun yang berjarak tanam 2 x 2 meter pada perlakuan $1(\mathrm{P} 1)=64,71 \%$, perlakuan $2(\mathrm{P} 2)=70,14 \%$, perlakuan $3(\mathrm{P} 3)=71,74 \%$, perlakuan $4(\mathrm{P} 4)=48,83 \%$, perlakuan $5(\mathrm{P} 5)$ $=65,11 \%$, perlakuan $6(\mathrm{P} 6)=49,12 \%$. Rata-rata persentase hidup tanaman jabon umur 6 
tahun dari hasil perhitungan menunjukkan bahwa rata-rata persentase hidup tanaman Jabon pada perlakuan P1, P2, P3, P4, P5, P6 yaitu rata-rata 61,61\% tergolong sedang. Perlakuan P4 persentase hidupnya 48,83\% tergolong kurang disebabkan sejak awal sudah banyak yang mati karena kekeringan dan solum tipis, akibatnya tanaman tumbuh tidak baik atau tidak sehat sedangkan P6 persentase hidupnya 49,12 \% karena banyak yang roboh karena angin. Hal ini dikemukakan oleh Daniel et al, 1970 bahwa dalam tahap perkembangan pertumbuhan tanaman dipengaruhi 2 faktor yaitu faktor genetik /keturunan dan faktor lingkungan. Faktor lingkungan yang berpengaruh adalah umur, kualitas tempat tumbuh, jenis tanaman, kerapatan tanaman atau jumlah pohon per hektarnya, dan perlakuan pada tegakannya. Sorianegara (1970) mengemukakan bahwa suatu jenis tanaman dengan faktor genetis sama, jika ditanam di lingkungan yang berbeda, maka hasil pertumbuhan akan berbeda, sebaliknya jika ditanam di lingkungan sama tetapi genetisnya berbeda,maka hasilnya juga berbeda. Penanaman tanaman apabila diharapkan hasilnya optimum, maka harus melakukan manipulasi faktor genetis dan faktor lingkungan. Tabel 2 dari hasil perhitungan serangan hama pada tanaman Jabon terdapat 2 jenis hama berupa ulat daun dan penggerek batang. Serangan hama yang ditunjukkan dengan intensitas serangan dan persentase kerusakan. Intensitas serangan hama ulat daun sebesar 100 $\%$ yang persentase kerusakannya relatif sangat ringan sebesar 8,89\%. Serangan ulat daun umumnya tidak menyebabkan tanaman mengalami kematian walaupun semua tanaman terserang, sedangkan penggerek batang sangat berbahaya. Serangan hama berupa penggerek batang menunjukkan bahwa Intensitas serangannya sebesar 5,26\% sangat kecil yang persentase kerusakannya cukup besar sebesar 41,67\%. Serangan hama penggerek batang sangat berbahaya karena umumnya menyebabkan kematian dan pohon mudah roboh jika ada angin besar. Untuk hama penggerek batang yang menyerang jabon umur 6 tahun bersifat mematikan pohon. Hal ini kemungkinan disebabkan jabon adalah jenis tanaman baru di lingkungan Widodomartani, dan jarak tanam yang terlalu dekat sehingga penularan hama relatif cepat.

\section{B. Tinggi Tanaman}

Tinggi Tanaman Jabon umur 6 tahun dari hasil perhitungan dan analisis hasilnya dapat dilihat pada Tabel 3 , Gambar 1 dan Tabel 4. 
Tabel 3. Rata-Rata Tinggi Tanaman Jabon (m)

\begin{tabular}{lrrrrr}
\hline \multirow{2}{*}{ Perlakuan } & \multicolumn{5}{c}{ Ulangan } \\
\cline { 2 - 5 } & \multicolumn{4}{c}{ II } & \multicolumn{3}{c}{ III } & \multicolumn{2}{l}{ Jumlah } & \multirow{2}{*}{ Rata-rata } \\
\hline P 1 & 15,33 & 15 & 18 & 48,33 & 16,11 \\
P 2 & 17,33 & 16,67 & 16,33 & 50,33 & 16,78 \\
P 3 & 16 & 14,67 & 15,67 & 46,34 & 15,45 \\
P 4 & 11,33 & 12,33 & 11,67 & 35,33 & 11,78 \\
P 5 & 14 & 13,33 & 13,33 & 40,66 & 13,55 \\
P 6 & 13,33 & 14,33 & 12 & 39,66 & 13,22 \\
\hline Jumlah & 87,32 & 86,33 & 87 & 260,65 & 86,88 \\
\hline Rata-rata & 14,55 & 14,38 & 14,5 & 43,44 & 14,48 \\
\hline
\end{tabular}

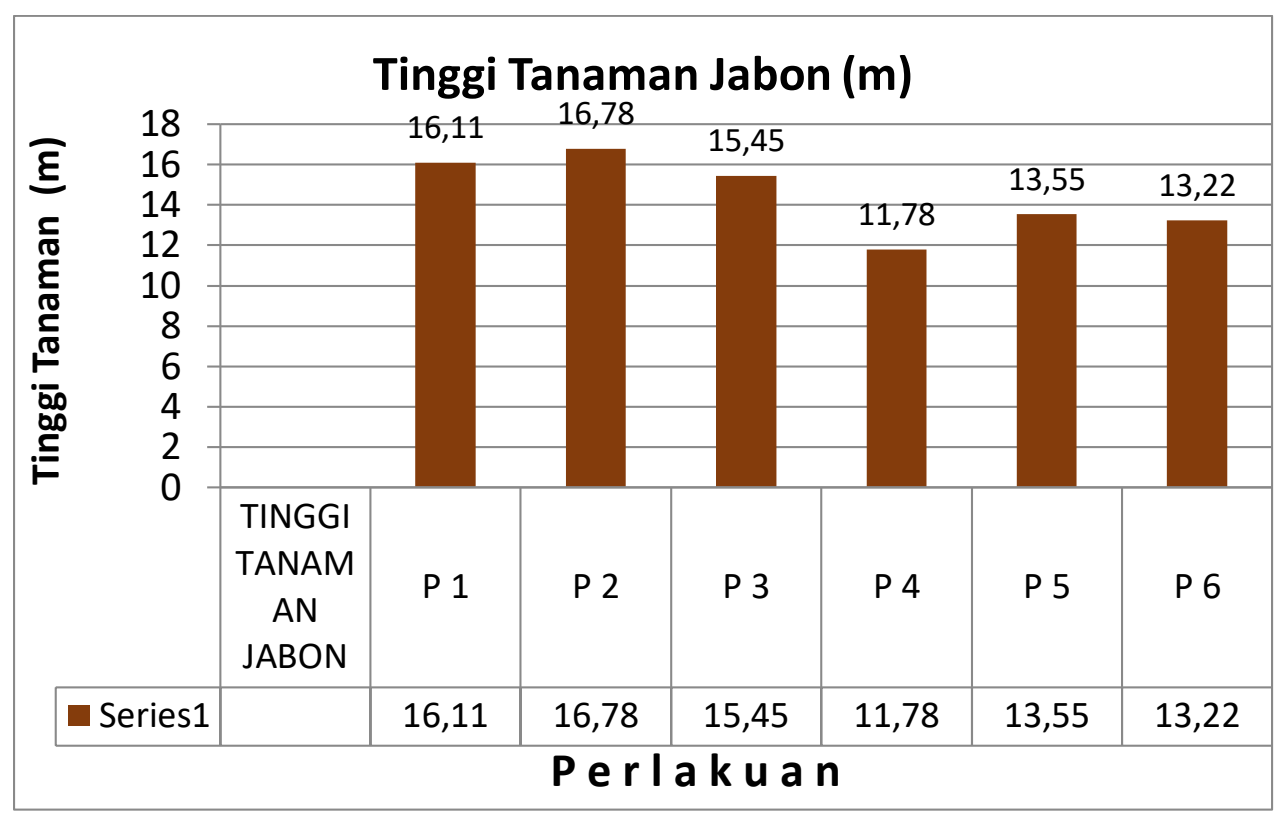

Gambar 1. Histogram Tinggi Tanaman Jabon Umur 6 Tahun Tabel 4. Hasil Sidik Ragam TInggi Tanaman Jabon Umur 6 Tahun

\begin{tabular}{lrllllr}
\hline \multirow{2}{*}{$\begin{array}{c}\text { Sumber } \\
\text { Perlakuan }\end{array}$} & \multirow{2}{*}{$\begin{array}{c}\text { Derajat } \\
\text { Bebas }\end{array}$} & $\begin{array}{l}\text { Jumlah } \\
\text { Kuadrat }\end{array}$ & $\begin{array}{l}\text { Kuadrat } \\
\text { Tengah }\end{array}$ & F Hitung & \multicolumn{2}{c}{ F Tabel } \\
${ } }$ & 5 & 55,86083 & 11,17217 & $3,21105^{*}$ & 3,11 & 5,06 \\
Galat & 12 & 10,43787 & 3,479289 & & & \\
& & & & & & \\
Umum & 17 & 66,2987 & & & & \\
\hline
\end{tabular}

Keterangan :

$*=$ Berbeda nyata pada taraf uji $5 \%$

Dari hasil analisis pada Tabel 4 menunjukkan ada pengaruh nyata lingkungan tumbuh tanaman terhadap tinggi tanaman jabon. Tinggi tanaman jabon pada P4 paling rendah yaitu 11,77 m dibanding dengan P1 (16,11 m), P2 (116,77 m), P3 (15,44 m), P5 (13,55 m), dan P6 $(13,22 \mathrm{~m})$. Tinggi rata-rata tanaman jabon umur 6 tahun adalah 14,48 m. Uji lanjut BNT dapat dilihat pada Tabel 5 . 
Tabel 5. Uji BNT Rata-rata Tinggi Tanaman Jabon pada Umur 6 Tahun

\begin{tabular}{ccc}
\hline Perlakuan & Tinggi Rata-rata & Nilai BNT 0,05 \\
\hline P1 & 16,11 bc & \\
P2 & 16,77 c & 3,316 \\
P3 & 15,44 bc & \\
P4 & 11,77 a & \\
P5 & 13,55 ab & \\
P6 & 13,22 ab & \\
\hline
\end{tabular}

Keterangan : Angka rata-rata yang diikuti huruf yang sama, menunjukkan tidak berbeda nyata pada taraf uji 0,05

Tinggi tanaman jabon ada kecenderungan makin baik pada lingkungan yang relatif lembab dan solum tebal. Tinggi tanaman jabon (Antocephalus cadamba) umur 6 tahun pada perlakuan $1(\mathrm{P} 1)=16,11 \mathrm{~m}$, perlakuan $2(\mathrm{P} 2)=16,77 \mathrm{~m}$, perlakuan $3(\mathrm{P} 3)=15,44 \mathrm{~m}$, perlakuan $4(\mathrm{P} 4)=11,77 \mathrm{~m}$, perlakuan $5(\mathrm{P} 5)=13,55 \mathrm{~m}$, perlakuan $6(\mathrm{P} 6)=13,2 \mathrm{~m}$. Tanaman pada P1, P2, P3, P5, P6 cukup baik dibandingkan dengan P4. Hasil rata-rata tinggi berbeda nyata menurut analisisnya, hanya P4 berbeda dengan P1, P2, P3, P5, P6. Hal ini disebabkan karena jarak tanam yang terlalu rapat dan juga karena kondisi solum yang tipis dan sejak awal tanam kondisi lebih kering. Tinggi tanaman jabon pada pertanaman ini masih cukup baik karena pada umumnya tanaman jabon sampai umur 8 tahun pertumbuhan tingginya 2-3 m per tahun. Kondisi ini sesuai dengan pendapat Daniel et al. (1979) yang menyatakan bahwa faktor lingkungan yang berpengaruh terhadap pertumbuhan adalah umur, kualitas tempat tumbuh, jenis tanaman, kerapatan dalam arti luas bidang dasar dan jumlah pohon per hektarnya. Selain itu juga dipengaruhi oleh perlakuan-perlakuan yang diterapkan dalam tegakan tersebut. Hal ini juga sesuai dengan pendapat Soerinegara (1970) yang menyatakan bahwa apabila suatu jenis tanaman mempunyai faktor sama tetapi ditanam pada lingkungan yang berbeda, maka akan memberikan hasil pertumbuhan yang berbeda dan Sabarnurdin (1979), bahwa Kecepatan meninggi sangat bervariasi menurut spesies, umur tanaman. Dalam pertumbuhan tanaman mengikuti kurva sigmoid, mempunyai percepatan pertumbuhan yang relatif pendek semasa seedling, dan percepatan pertumbuhan yang paling besar pada waktu muda dan periode panjang dengan pertumbuhan yang dapat diabaikan pada waktu tuanya

\section{Diameter Tanaman}

Diameter tanaman jabon dari hasil perhitungan dan analisis hasilnya dapat dilihat pada Tabel 6, Gambar 2 dan Tabel 7 serta Tabel 8. 
Tabel 6. Diameter Tanaman Jabon umur 6 Tahun $(\mathrm{cm})$

\begin{tabular}{|c|c|c|c|c|c|}
\hline \multirow{2}{*}{ Perlakuan } & \multicolumn{3}{|c|}{ Ulangan } & \multirow{2}{*}{ Jumlah } & \multirow{2}{*}{ Rata-rata } \\
\hline & I & II & III & & \\
\hline P 1 & 16,56 & 14,75 & 18,89 & 50,2 & 16,73 \\
\hline P 2 & 18,78 & 12,42 & 15,92 & 47,12 & 15,70 \\
\hline P 3 & 14,65 & 14,43 & 22,08 & 51,16 & 17,05 \\
\hline P 4 & 13,58 & 13,59 & 12,52 & 39,69 & 13,23 \\
\hline P 5 & 14,01 & 10,72 & 10,72 & 35,45 & 11,81 \\
\hline P 6 & 12,63 & 13,27 & 13,37 & 39,27 & 13,09 \\
\hline Jumlah & 90,21 & 79,18 & 93,5 & 262,89 & 87,63 \\
\hline Rata-rata & 15,04 & 13,19 & 15,58 & 43,81 & 14,61 \\
\hline
\end{tabular}

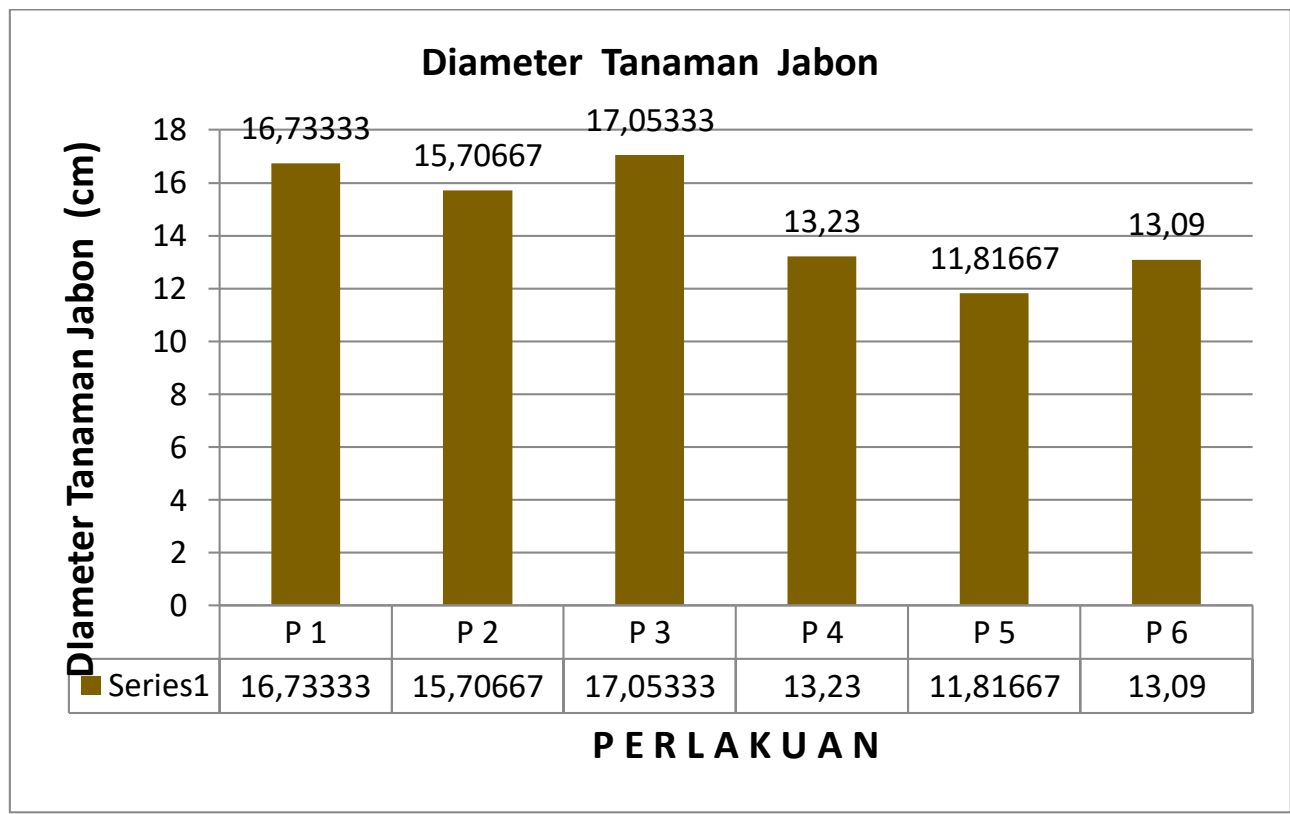

Gambar 2. Histogram Diameter Tanaman Jabon Umur 6 Tahun

Diameter tanaman jabon (Antocephalus cadamba) pada umur 6 tahun dalam Tabel 6 dan gambar 2 menunjukkan bahwa pada perlakuan $1(\mathrm{P} 1)=16,73 \mathrm{~cm}$, perlakuan $2(\mathrm{P} 2)=15,71$ $\mathrm{cm}$, perlakuan $3(\mathrm{P} 3)=17,05 \mathrm{~cm}$, perlakuan $4(\mathrm{P} 4)=13,23 \mathrm{~cm}$, perlakuan $5(\mathrm{P} 5)=11,82 \mathrm{~cm}$, perlakuan $6(\mathrm{P} 6)=13,09 \mathrm{~cm}$. Hasil sidik ragam pada rata-rata diameter Jabon dapat dilihat pada tabel 7 yang hasilnya berbeda nyata.

Tabel 7. Hasil Sidik Ragam Diameter Tanaman Jabon

\begin{tabular}{lrllllrr}
\hline $\begin{array}{c}\text { Sumber } \\
\text { Perlakuan }\end{array}$ & \multirow{2}{*}{$\begin{array}{c}\text { Derajat } \\
\text { Bebas }\end{array}$} & $\begin{array}{c}\text { Jumlah } \\
\text { Kuadrat }\end{array}$ & $\begin{array}{l}\text { Kuadrat } \\
\text { Tengah }\end{array}$ & F Hitung & \multicolumn{2}{c}{ F Tabel } \\
\cline { 5 - 7 } Perlakuan & 5 & 136,2468 & 27,24937 & $8,193765^{* *}$ & 3,11 & 5,06 \\
Galat & 12 & 9,976867 & 3,325622 & & & \\
Umum & 17 & 146,2237 & & & & \\
\hline
\end{tabular}

Keterangan :

$* *$ = Berbeda sangat nyata pada taraf uji $1 \%$ 
Dari hasil analisis pada Tabel 7 menunjukkan adanya pengaruh nyata lingkungan tumbuh tanaman terhadap diameter tanaman jabon. Untuk melihat pengaruhnya yang ditunjukkan dengan diameter berbeda, harus dilanjutkan dengan uji BNT agar dapat dilihat perbedaannya atau beda nyatanya dapat dilihat pada Tabel 8 ..

Tabel 8. Uji BNT untuk Rata-rata Diameter Tanaman Jabon pada Umur 6 Tahun

\begin{tabular}{llll}
\hline & Perlakuan & \multicolumn{3}{c}{ Tinggi Rata-rata } & Nilai BNT 0,01 \\
\hline P1 & 16,733 & b & \\
P2 & 15,707 & ab & \\
P3 & 17,053 & b & 4,548 \\
P4 & 13,230 & ab & \\
P5 & 11,816 & a & \\
P6 & 13,090 & ab & \\
\hline
\end{tabular}

Keterangan: Angka rata-rata yang diikuti huruf yang sama, menunjukkan tidak berbeda nyata pada taraf uji 0,01

Kondisi diameter tanaman jabon pada Tabel 8 menunjukkan bahwa pada P1, P2 dan P3 lebih baik daripada P4, P5, dan P6. Hal ini disebabkan karena pada P5 dan P6 jarak tanam yang terlalu rapat dan kurang sinar matahari serta tanaman yang bagus banyak yang ditebang kecuali P4 yang sejak awal kondisi lingkungannya jelek (solum tipis dan mudah kering dekat sampai yang dalam. Kondisi ini sesuai dengan pendapat Daniel et al. (1979), bahwa pada tahap perkembangan faktor lingkungan yang berpengaruh terhadap pertumbuhan adalah umur, kualitas tempat tumbuh, jenis tanaman, kerapatan dalam arti luas bidang dasar dan jumlah pohon per hektarnya, selain itu juga dipengaruhi oleh perlakuan-perlakuan yang diterapkan dalam tegakan tersebut. Kramer dan Kozlowski (1978) berpendapat bahwa pertumbuhan diameter lebih dipengaruhi oleh fluktuasi keadaan lingkungan.

Pertumbuhan membesar (pertambahan diameter pohon) disebabkan oleh kegiatan suatu kambium kambium vaskular, kambium sekunder, atau kambium lateral, yaitu suatu jaringan yang selalu membelah diri yang terletak di antara lapisan xilem dan floem. Pertumbuhan yang dihasilkan oleh kambium vaskuler disebut pertumbuhan sekunder atau penebalan sekunder batang. Jaringan (xilem dan floem) yang berasal dari kambium sekunder ini disebut jaringan sekunder. Pertambahan lapisan xilem ini menyebabkan pertambahan diameter batang (Prawirohatmodjo,1999).

\section{Pertumbuhan Tanaman Jabon}

Dari hasil perhitungan pertumbuhan tanaman jabon secara keseluruhan didapatkan hasil yang cukup baik karena rata-rata persentase hidup 61,61 \% (sudah banyak yang ditebang), tinggi tanaman 14,48 $\mathrm{m}$ dan diameter 14,61 cm. Dari perlakuan yang ada di lapangan, maka P2 menunjukkan hasil yang paling baik pada parameter tinggi tanaman (rata-rata $=16,77 \mathrm{~m}$ ) 
dan P3 menunjukkan hasil yang paling baik pada parameter diameter pohon (rata-rata $=17,05$ $\mathrm{cm})$. Dengan jarak tanam $2 \times 2 \mathrm{~m}$ umur 6 tahun hasil volume per hektar adalah $2.500 \times 0,057$ $\mathrm{m}^{3}=142,50 \mathrm{~m} 3$ termasuk baik. Hasil baik ini akan lebih baik lagi jika setelah umur 4 tahun pohon yang dilakukan penjarangan untuk yang kurang baik dan perawatan dari hama penggerek serta gulma merambat . Kondisi ini sesuai dengan pendapat Daniel et al. (1979), bahwa pertumbuhan merupakan pertambahan ukuran yang bersifat tetap dari berbagai sifat fisiologis. Pertambahan ukuran ini terjadi karena pembelahan dan perkembangan sel yang menjadi jaringan organ pada akhirnya menjadi tanaman dewasa. Pertumbuhan tegakan dipengaruhi oleh berbagai faktor yaitu faktor dalam tanaman (faktor genetik/keturunan), dan faktor lingkungan. Pada tahap perkembangan faktor lingkungan yang berpengaruh terhadap pertumbuhan adalah umur, kualitas tempat tumbuh, jenis tanaman, kerapatan dalam arti luas bidang dasar dan jumlah pohon per hektarnya, selain itu juga dipengaruhi oleh perlakuanperlakuan yang diterapkan dalam tegakan tersebut.

\section{KESIMPULAN}

1. Intensitas serangan hama ulat daun sebesar $100 \%$ dengan persentase kerusakannya relatif sangat ringan sebesar 8,89\% dan penggerek batang Intensitas serangannya sebesar 5,26\% sangat kecil dengan persentase kerusakannya cukup besar sebesar 41,67\%.

2. Pertumbuhan tanaman jabon (Antocephalus cadamba) pada umur 6 tahun yang berjarak tanam 2 × 2 meter di Widodomartani, Ngemplak, Sleman cukup baik dengan persentase hidup $61,61 \%$, tinggi tanaman $14,48 \mathrm{~m}$ dan diameter $14,61 \mathrm{~cm}$ dan volume $142,50 \mathrm{~m}^{3} / \mathrm{ha}$ termasuk baik.

\section{DAFTAR PUSTAKA}

Anonim. 2010 a. Jabon. Direktorat Perbenihan Kementrian Hutan. 2010 b. Jabon Jagoan Kayu Produktif. PT. Trubus Swadaya.

Daniel, T.N., J, A. Helms dan F.S Baker, 1979. Prinsip Silvikultur. Mc Graw Hill Book Company, Terjemahan. Gadjah Mada University, Jogjakarta.

Hanafiah, K. 2014. Rancangan Percobaan, Teori dan Aplikasi. PT.Rajagrafindo Persada. Jakarta.

Kabe, Abigael, Wayan Darmawan, dan Muh. Yusram Massijaya. 2013. Ciri Vinir Kupas Kayu Jabon (Anthocephalus cadamba). Jurnal Ilmu Pertanian Indonesia (JIPI). Desember 2013. Lembaga Penelitian dan Pengambanagan Kepada Masyarakat IPB.Kampus IPB Darmaga.

Kramer, P.J.N. and T.T. Kozlowski, 1979. Physiology of Tress. Mc Graw-Hill Book Ocmpany Inc. New York.

Mansur, I. dan F.D. Tuheteru, 2011. Kayu Jabon. PT. Penebar Swadaya. Yogyakarta. 
Mintarjo. 2018. Prospek Industri Kayu Ringan di Indonesia. Personal Communication. Owner PT. Abioso Batara Alba Wood Working Industry.Boyolali, Jawa Tengah.

Mulyana, Dadan; C.Asmarahman dan I.Fahmi.2012. Jabon dan Sengon (Petunjuk Praktis Pembibitan).Agromedia Pustaka .Cetakan ke-1. Jakarta.

Prawirohatmodjo, S., 1999. Struktur dan Sifat Kayu. Yayasan Pembina Fakultas Kehutanan Universitas Gadjah Mada. Jogjakarta.

Prijono, A., 2013a. Pertumbuhan Tanaman Jabon (Anthocepalus cadamba) Sebagai Jenis Cepat Tumbuh di Lapangan. Fakultas Kehutanan INSTIPER Yogyakarta.

. 2013b. Pertumbuhan Tanaman Jabon (Anthocepalus cadamba) Sebagai Jenis Cepat Tumbuh Sampai Umur 30 Bulan di Lapangan. Fakultas Kehutanan INSTIPER Yogyakarta.

.2016. Pertumbuhan dan Serangan Hama pada Tanaman Jabon (Antocephalus cadamba) Umur Empat Tahun. Jurnal Wana Tropika.Vol.6 No. 1, Februari 2016.Halaman 15 - 28.ISSN: 2088-7019. Penerbit Fakultas Kehutanan Institut Pertanian Stiper .Yogyakarta.

Sabarnurdin, S. 1979. Phisiologi Pohon. Yayasan Pembina Fakultas Kehutanan Universitas Gadjah Mada. Jogjakarta.

Setyaji, Teguh. 2011. Jabon 'si Jati Bongsor' Dan Prospeknya Untuk Hutan Rakyat.Informasi Teknis. Vol. 9 No. 2, September 2011. Balai besar Penelitian Bioteknologi dan Pemuliaan Tanaman Hutan. Yogyakarta.

Soerianegara, I. 1970. Pemuliaan Hutan. Lembaga Penelitian Hutan. Bogor.

Sulaksono, T.N., H.B. Woesono, dan A. Prijono,. 2013. Evaluasi Pertumbuhan Tanaman Jabon (Anthocepalus cadamba) pada Berbagai Lokasi. Fakultas Kehutanan INSTIPER Yogyakarta.

Sumarno, Agus. 2012. Sengon dan Jabon Kayu Super Cepat. Penebar Swadaya. Cetakan Ke1. Yogyakarta.

Suprihanto, B. 2013. Prospek Perkayuan Indonesia. Personal Communication. General Manager PT Kendal Indah Perkayuan Indonesia.

Wahyudi. 2012. Analisis Pertumbuhan Dan Hasil Tanaman Jabon (Anthocepalus cadamba). Jurnal Perennial, 2012. Vol. 8 N0. 1: 19-24. ISSN: 1412-7784GM. Yogyakarta. 